\title{
AI TRIAGE - HELPING FALTERING STUDENTS REHABILITATE FROM ACADEMIC MISCONDUCTS
}

\author{
Zeenath Reza Khan, Tina Ann Thomas, Vidhi Sharma
}

Key words: Academic Integrity, Misconduct, Cheating, Contract Cheating, Triage, Support Students

\section{Introduction}

Academics globally are constantly faced with situations where they have to confront students who may or may not have committed academic misconduct. Academic misconduct is any action that someone commits, thereby giving them an unfair advantage over others in an academic setting. Amidst various types of misconduct exist cheating, fraud, interference, collusion, fabrication and plagiarism (UOW, 2019).

Literature indicates that "academic dishonesty appears to be a precursor to workplace dishonesty" (Muola et. al, 2018). Students who have engaged in some form of academic dishonesty could possibly be involved in "dishonest activities in the workplace" (Muola et. al, 2018). In addition, these individuals could cause "irreversible damage to their colleagues" and hamper the reputation of the organization they work for (Muola et. al, 2018).

Hence, educational institutions upholding academic integrity have two purposes:

1. to help students accomplish the skills needed for their chosen career, and

2. to promote an ethical viewpoint which guides decision-making

(Guerrero-Dib et. al, 2020)

There are a number of measures that educational institutions take to curb academic misconducts. This paper explains how some universities detect these misconducts and enforce penalties in order to curb them. It is also essential to think about the impact of academic misconduct accusations and their subsequent consequences on students. Since research carried out regarding this is scarce, this paper proposes to take a look into this and how best to support students who are accused of misconduct at higher education.

\section{Literature Review and Background}

According to the International Center for Academic Integrity, "honesty, trust, fairness, respect, responsibility, and courage" are the core values of academic integrity (ICAI, 2020). These values of honesty, trust, fairness, respect and responsibility in addition to the courage that is required to act upon them lays the groundwork for academic committees to translate these principles into desired behaviors in classrooms and beyond (ICAI, 2020).

Academic professionals all over the world uphold these fundamental values of academic integrity because they understand that the "final goals of teaching, learning 
and research can only be accomplished in environments in which ethical standards are upheld" (ICAI, 2020).

\section{Academic Integrity - Importance in Higher Education Settings}

According to Guerrero-Dib et. al (2020), teaching academic integrity at university level goes beyond teaching students to avoid deceitful acts such as "copying during exams, plagiarizing or contract cheating”. Instilling academic integrity values entails teaching students the importance of using sincere effort and honest means to achieve the best they can. These values go a long way in helping individuals develop "an ethical perspective for principled decision making it applicable to any context" (ibid) thereby preparing them to make ethical decisions in their respective workplaces.

Literature indicates that an increasing number of university students are involved in some practices of cheating (Newstead 1996 in Brodowsky et. al, 2020). Students are diversifying in terms of how and why they indulge in dishonest practices at university. In order to help students, professors need to understand students' attitudes towards these dishonest practices and also gauge the reasons they indulge in cheating (Brodowsky et. al, 2020).

There are several reasons why students indulge in cheating. According to Whitney and Keith-Spiegel, the following are some of the factors that cause students to practice academic dishonesty:

- Peer pressure

- Performance Anxiety

- Inability to multitask / manage deadlines.

- Failing to comprehend terms such as plagiarism, paraphrasing, etc.

- Failing to understand the serious implications of being caught cheating.

(Whitney \& Keith-Spiegel in NIU, 2019)

Comprehensive studies such as Khan (2014) also posited over 39 factors that might influence students' likelihood to e-cheat (electronic cheat).

Academics have tried to curb misconduct through various proactive and reactive measures such as:

- Instilling the fear of getting caught

- Talking more about academic dishonesty and the consequences

- Discussing personal consequences in the long run such as getting caught during a job interview

- Empowering honest students to influence their peers

- Introducing a class honor code for major courses, capstones and/or senior seminars in line with professional standards

- Changing assessment designs

(Weimer, M., 2018) 


\section{Role of Detection and Importance of Penalty}

According to Shore (2020), in order for universities and other high educational institutions to promote academic integrity, it is essential for them to not only detect and curb misconducts, but also just as important to respond to these misconducts in an appropriate manner.

Responding to academic misconducts and imposing penalties is essential because by doing so, the academic faculty "sends an important message to other students about the consequences of cheating" (Shore, 2020). Failure in enforcing penalties may result in other students believing that these practices are the norm thereby turning them into cheaters too. However, subjecting students to penalties without assessing the reason behind their behaviors may result in those students continuing the practices of academic misconduct. Hence, academic professionals should emphasize on not only detecting and reporting these misconducts but also correcting the problems underneath these behaviors (Shore, 2020).

Regardless of the approach undertaken, there remain times when faculty members have to confront situations where students have faltered intentionally or unintentionally and committed misconduct, and "arrange for investigation and inquiry, as appropriate" (Flinders University, 2019).

"Society cannot afford to watch academic dishonesty keep on increasing ... [as the] Widespread abuses of academic integrity may lead to endemic corruption" (Muola et. al, 2018). It is mandatory to have detection techniques in place to help reemphasize "the norms and core values of the institution and community" (Muola et. al, 2018), thereby, avoiding the chance of placing "independent thinking, intellectual property, the struggle of original thought, and academic freedom ... at risk” (Muola et. al, 2018). Ways to detect and address academic dishonesty include:

- Whistle Blowing: Encouraging students through "maintaining standards, the perception that the perpetrator needed help, personal morality and upholding student honor codes" (Wood, 2010) would motivate them to report anyone known to practice academic fraud. There is definitely a need for proof before a decision is made and although, "Historically, whistle blowers have not been protected" (Wood, 2010), it is mandatory to reassure students against their "fear of retaliation by peers and the belief that it is not their responsibility" (Wood, 2010).

- Software Tools for Text Matching: "Academic institutions now have access to many online detection services that help detect and curtail student fraud" (Wood, 2010). Despite the fact that these services can provide "false positives" possibly due to "limited scope" and "technical restrictions", these services have proven to be successful especially when utilized in conjunction with the judgement of the assessor (Wood, 2010).

- Policy Implementation and Practice: Higher education institutions should have academic integrity policies that are regularly revisited through workshops, training programs and learning modules, thereby "[creating] awareness of the potential problems of academic fraud [while] continually [reminding] students about how unacceptable the practice is" (Singh, 2016). As a result, students cannot make 
claims of ignorance such as "not [being] appropriately informed, that plagiarism would be regarded as academic misconduct" (Singh, 2016).

- Proctoring and Invigilation: This detection technique is largely useful when monitoring the integrity of a student's work as it ensures that the faculty is closely involved at various points of an assessment. For example, "a dissertation should be almost co-created by a student and his or her supervisor, with the student doing the work and the supervisor keeping a close eye on what is happening step-by-step" (Singh et. al, 2016), thus guaranteeing "relatively little opportunity for plagiarism to escape unnoticed" (Singh et. al, 2016).

- Personal Involvement: Ghostwriting is not new to the field of literature and is the act of "hiring a writer (or writers) to produce a piece of work that follows a predefined style, and none of the original writing credit is attributed to the ghostwriter. ... Although ghostwriting is not illegal, lying about the authorship of a piece of work is potentially fraudulent" (Singh et. al, 2016). Software detects plagiarism but has not been proven to be successful in the case of ghostwritten work. Hence, "lecturers having personal knowledge of the capabilities of their students" (Singh et. al, 2016) is the best form of detection of ghostwriting. A personal involvement equipped with "a greater number of oral examinations" (Singh et. al, 2016) would definitely help in detecting ghostwriting as the lecturer or supervisor would in due course be "personally acquainted with the student's level of subject knowledge and his or her natural writing style" (Singh et. al, 2016).

However, regardless of the detection technique adopted and prevailing attempts to curb misconduct, literature shows that "the vice continues to persist" (Muola et. al, 2018). It is mandatory to have the consequences strictly practiced in order to further stress on the importance of academic integrity and this may "range from requiring the student to resubmit the piece of work to suspending or even expelling him or her from the university" (Singh et. al, 2016). Suggested techniques include:

- Changing Assessment Strategies: The power of the Internet gives an "ease with which students can" cut and paste "content from online sources" (Wood, 2010) and lose their purpose of learning. Assessing a student should ideally be a continuous process as that gives a feeling of connectivity. Further, it defines a purpose that would make the student "become highly engaged with their subject material, and to express their creativity in such a way that it would be apparent who has succeeded in the learning process and who has not" (Singh et al, 2016). Thus, altering the assessment strategy "places the emphasis on the product rather than on the process of creating it" (Wood, 2010).

- Imposing Penalties: Wood (2010) has mentioned "the possibility of varying degrees of plagiarism", which implies that "differing offenses should be ranked and assigned appropriate consequences" (Wood, 2010). Also, the assessor should use their own judgement to detect possible human error and the level of penalty should definitely be in proportion to the severity of the crime. "For example, if 2 or 3 lines of text were plagiarized, the penalty might be only warning the student. For borrowing and copying a complete text, the penalty would be more severe, and for stealing 
another's work, the penalty should be dismissal" (Wood, 2010). Thus, academic professionals should stress on the importance of academic integrity, have their students agree to not practice academic dishonesty, rank levels of misconduct and assign relative penalties, and ensure they gather sufficient evidence before imposing the penalty (Wood, 2010).

Research conducted by Koletsi-Kounari et. al (2011) about penalties for academic dishonesty in a Greek dental school environment proves that decisions are subject to individual opinions and influenced by the level of professionalism. There is no fixed standard or set of quantitative values against which penalties may be weighed, thereby requiring further research in the area.

\section{Impact of detection and penalty}

Research has posited ways by which confrontations, investigations and inquiry impact students. Some studies have highlighted the following:

- Social shame: When a student cheats or is caught cheating, word often spreads across the school or university. This "taints the student's reputation and cause people to question his or her work in the future" (Thompsun, n.d.).

- Denial of responsibility: Students deny taking any responsibility for their actions by insisting that "their cheating was accidental" and they didn't know they were cheating in the first place (Olafson et. al, 2013).

- Condemnation of the faculty involved: Upon being caught cheating, "students generally deflect blame externally, blaming the instructor for unfairness or poor teaching or unclear grading rubrics" (Olafson et. al, 2013).

- Psychological negativity: Students also experience guilt after being caught plagiarizing or cheating (Ballantine et. al, 2018).

In 2018, a school student accused of cheating in exams, committed suicide in Dhaka, Bangladesh (Rabbi, 2018). A series of mishandling of the situation including humiliation of parents at the hands of the top management led to the student ultimately committing suicide. In 2019, following a cheating scandal for the California Practice Standards and Jurisprudence Examination for Pharmacists (CPJE), thousands of students stated they had contemplated suicide (Gonzalez, 2019).

It thus becomes vital that institutions provide due support, given the consequences and impact of detection and penalty levied on students - to students when alleged accusations are brought on for misconduct. Although studies have focused on falsely accused students, very little is said about support provided or that should be provided for students who may have in fact committed misconduct.

Thus, the objective of this research includes the following:

- Curating a support system for students who have faced allegations, are currently involved in the process of investigation and for students who have completed the process.

- Recording the impact of said support system on students. 


\section{Methodology, Results, Analysis and Discussion}

This paper tracks attempts by faculty who have adopted the concept of a "triage" to develop a support system for all students who face allegations. The first objective of the paper is to curate such a support system.

\section{Developing a Support System}

The word 'triage' stems from the French word trier, which means 'to sort'. According to Lasky, triage is the method that is used in clinics and hospitals to prioritize patients on the basis of how urgent their need for treatment is (Lasky, 2017). When medical staff have limited resources during medical emergencies or war, they use triage as a method of "quickly assessing patients' conditions and ensuring that those in the most serious condition receive treatment first" (Lasky, 2017).

Higher education institutes such as universities have also adopted the triage approach to offer support to students, thereby enabling them to make the most of their university experience. For instance, Ulster University uses triage staff who have been trained to "have an in-depth knowledge of [their] Student Support services" (Ulster University, N.D.). This ensures that "students are seen faster and receive relevant information to support them with their particular issue" (Ulster University, N.D.). In addition, "Triage assistants have also been trained to provide immediate care and support for students in distress" (Ulster University, N.D.). Thus, it may be generalized that triage systems offered by universities cover general health and wellbeing, sexual health, financial and budgeting advice, academic advice and counselling, mentoring networks and disability support (Maria, N.D.).

\section{Curated support system}

For a western university in a Middle Eastern country, the lead faculty trained two faculty members and developed an "Academic Misconduct Case Triage". This mimics the same process from an emergency room in a clinic or hospital to deal with students who have faltered in complying with academic integrity requirements at tertiary education levels.

The triage uses a simple model. As a pilot, the triage was rolled out in two firstyear subjects across two semesters. At the beginning of the semester, the students were informed of the support system in place after the academic integrity policy was explained, along with a short over-view workshop on academic writing. During the semester, if a student received an email informing him/her of a possible allegation, then and after their meeting they were invited to contact the triage for support. A meeting would be set up where faculty could speak to the student. Alternatively, the student had the option to request for a virtual meeting through the learning management system's "link only" option that did not require any sign in. The conversation was always positive; never accusatory. Faculty engaged students, making them feel safe to discuss the case. If, at any point, the faculty felt further assistance was required, then the faculty guided the student to approach the counsellor. At the end of the hour of consultation, the faculty provided the student with tips on academic writing, particularly on how to rectify mistakes made in previous assignment(s). If the faculty felt the student may have 
been accused wrongly, the faculty advised the student on the policy and to approach the faculty office to understand the appeal process. Figure 1 illustrates the triage model adopted for the research.

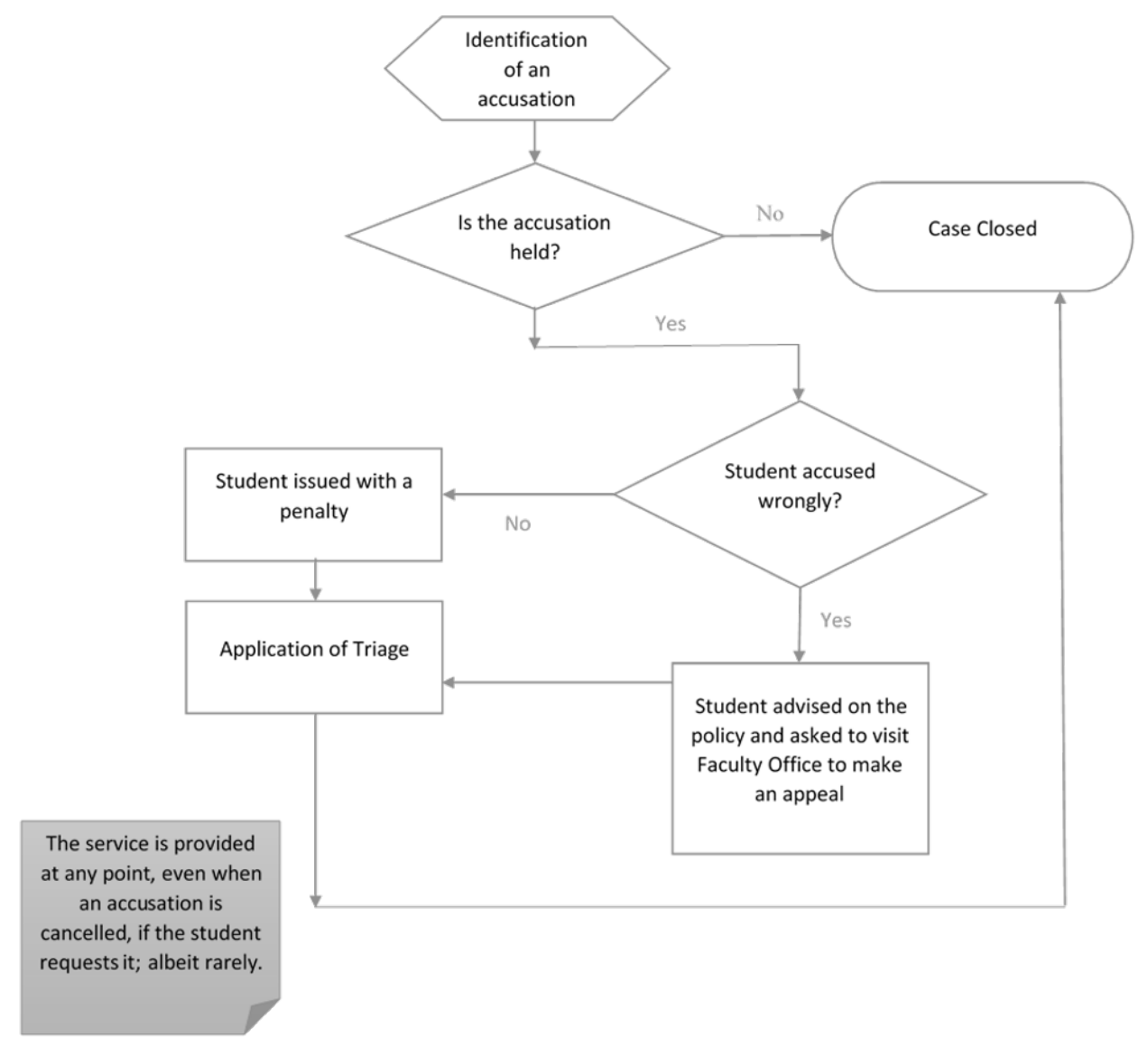

Figure 1. Model of Curated Support System

Recording the impact

The second research objective of this study is to record the impact of said support system on students. In order to track the impact of the support system implementation, the faculty involved acquired necessary approvals, designed flyers and circulated the offer of such a service to students on campus. Students who sought out the support system were asked to provide tacit consent to record their feedback anonymously using the university feedback form.

In the two semesters that the triage was introduced across the two subjects, three faculty members were approached by students, leading to a total of 79 cases that were 
offered support. All cases were deemed legitimate. All 79 students used the time to speak to the faculty, and build a rapport.

\section{Results and Discussions}

The rate of response was clocked at 53 out of 79 , which is $67 \%$. According to Ohme et. al (2005), 66\% response rate is suggested as acceptable while researchers such as Love and Smith (2003), and Liberatore et. al, (2001) suggested 30\% as viable and satisfactory. Based on literature, the current rate of $67 \%$ was viable and acceptable for this study.

The feedback was captured on a 3-point scale with point 1 representing those who disagree to the system, point 2 being neutral and point 3 as those agreeing. Students provided feedback to queries such as "how did you feel after the session", "was the session helpful", "what was the most useful part of the session", "what was the least useful part of the session" and so on. Not all students who used the triage session gave feedback. The results are illustrated in Figure 2 - Summary of Feedback on Curated Support System.

The effectiveness of the curated support system was recorded through faculty interview and observations. This included feedback such as "students opened up when they felt comfortable", "some students asked for more time and came back to talk more about integrity in education", "students felt safe to cry", "students accepted they did not understand the mistake" and so on.

While majority agreed to the effectiveness of the system, with 96\% stating that the "triage session was much needed", $11 \%$ were neutral about the session having "provided clear understanding of the issue" and 8\% disagreed to the session being "comforting" and "support person was knowledgeable".

Around $83 \%$ responded that the triage session "provided clear understanding of the issue" while $8 \%$ were neutral about the session being "helpful" and $9 \%$ about the session having given "guidance that was supportive", and 6\% disagreed to the session as having "provided clear understanding of the issue".

Approximately $87-91 \%$ of the respondents agreed that the "support person was knowledgeable", "session gave guidance that was supportive", "session was comforting" and "session was helpful", 2-4\% were neutral about the session being "much needed" and "comforting", and "support person was knowledgeable", and 2-4\% disagreed that the session was "much needed", "helpful" and "gave guidance that was supportive".

With reference to the above figures and graphical illustration, it is evident that a standard deviation of 2.6 only $4.72 \%$ respondents disagreed to the effectiveness of the curated support system.

$6.29 \%$ were neutral in their feedback about the system and observed a standard deviation of $3 \cdot 71$.

Hence, the majority of $88.99 \%$ agree that the triage system is highly effective and observe a standard deviation of only 4.37 .

Qualitative analysis of student comments revealed that students felt the sessions were "great", "very useful", "needed", "saved me", "got to vent". Other comments included "the session helped me see how I went wrong and how I can correct the mistake", "I did not feel shame", "I think this session was a great idea because I felt like someone listened 


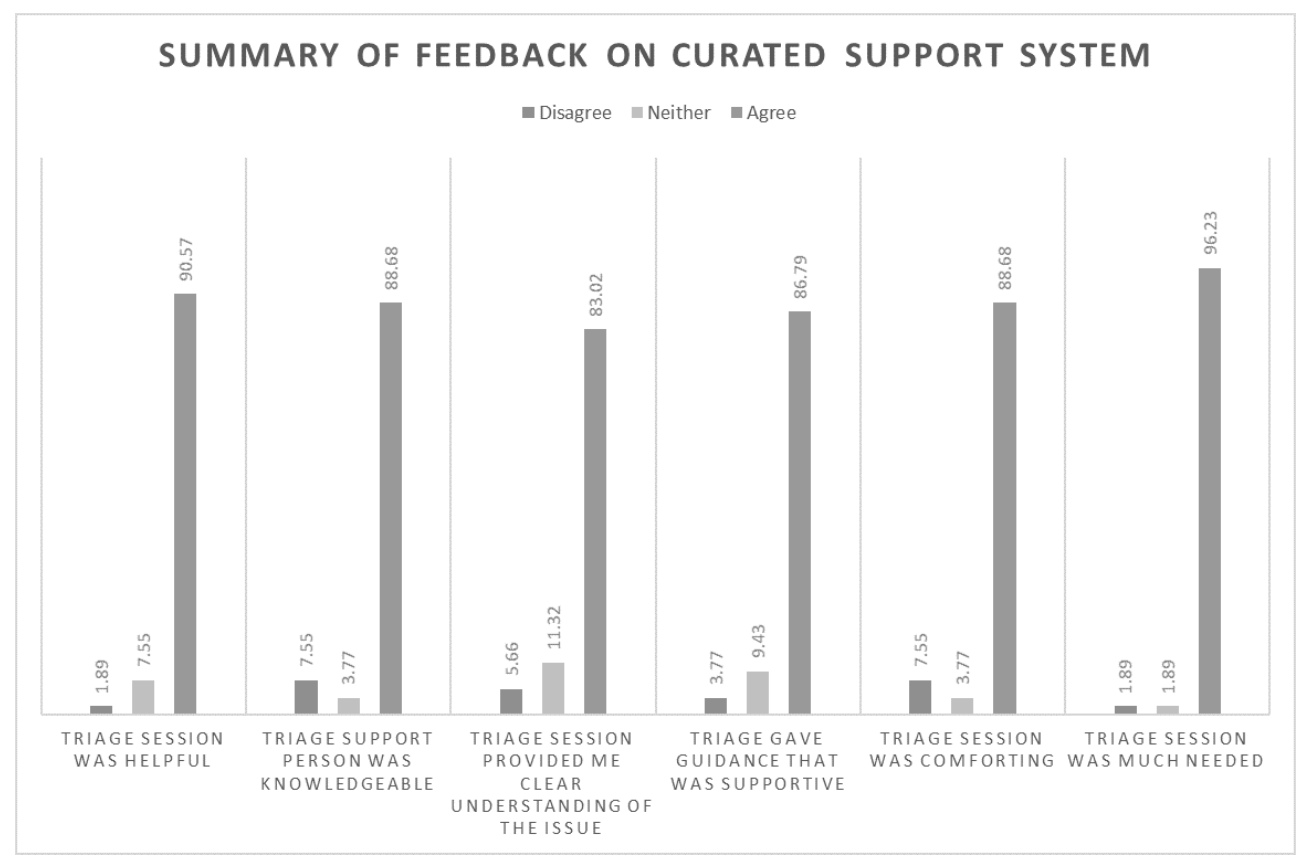

Figure 2. Summary of Feedback on Curated Support System

to me" "I did not feel judged" and so on. Although some felt that the "session was long", this may be treated as the least relevant of feedbacks. These results have been depicted in Figure 3 - Triage: Student Feedback Word Cloud.

\section{Understanding the Triage word cloud}

A word cloud is essentially "a visual representation of frequency of words. The more commonly the term appears within the text being analyzed, the larger the word appears in the image generated" (Atenstaedt, 2012). Word clouds are a particularly beneficial tool in analyzing qualitative data because they are impactful in structuring textual data, which in turn makes it visually appealing, easy to comprehend and simple to share (McKee, 2014).

Word clouds are often used by researchers to convert qualitative insights into computable analytics. In 2012, USA Today used a word cloud based on President Obama's State of Union Speech, which underlined the most powerful words that were used during his address to the nation (USA Today, 2012).

Hence, a picture is clearly worth a thousand words and the words in larger font within Figure 3 highlight those that were used most frequently in the student responses. This proves the effectiveness of the triage system and helps conclude that it is vital to have such a system in place for the management and resolution of academic misconduct cases. 


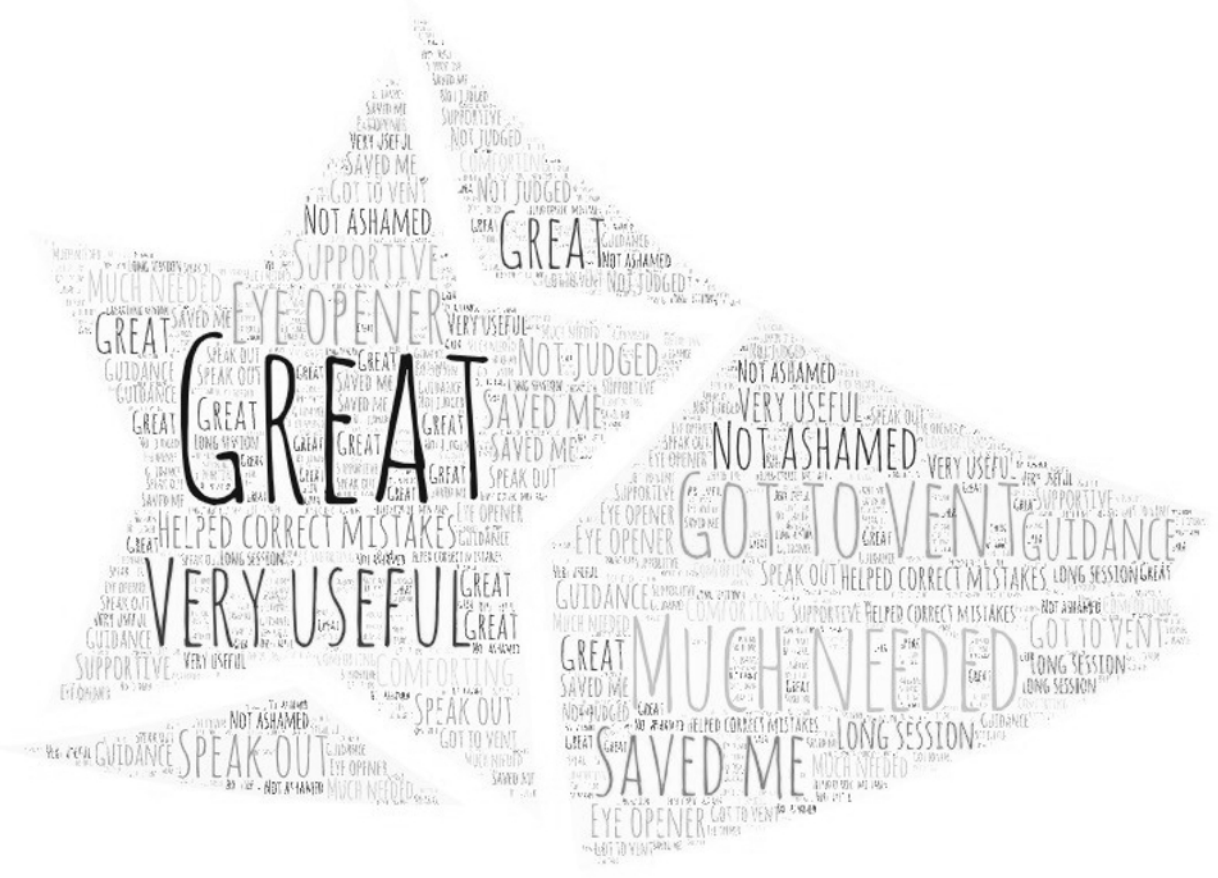

Figure 3. Triage: Student Feedback Word Cloud

\section{Conclusion}

In summary, academic misconduct in schools and universities tend to create disturbances in a student's life, which is why it is so important for faculty to detect and levy penalty. However, literature shows that penalties and also just detection can sometimes have a negative effect on the student's emotional, social and psychological wellbeing (Thompsun, n.d.). Since there has been little focus on students who have indulged in academic misconduct and the support available for them as well as those who have been victims of false accusation or plagiarism, this study has focused on such cases.

The research resulted in the development of a support system named Triage, which after two rounds of implementation and receiving feedback from students has proven that triage for academic misconduct cases is not only a success, but much needed in higher education institutions. The results highlight some very strong and positive responses from the students who attended the triage sessions. They left feeling content that they were not being targeted, but rather walking away having taken ownership of their mistake and learning integrity in the process. 
The faculty plan to carry out two more semesters that will have a different set of students to see if the results are consistent with this round. If so, future plans include rolling out the triage for other subjects.

\section{References}

Atenstaedt. (2012). Word Cloud Analysis of the BJGP, British Journal of General Practice, Vol. 62, (598), p 148, Available at: https://www.ncbi.nlm.nih.gov/pmc/articles/PMC3289811/ [Accessed 23rd May 2020]

Ballantine, ET AL. (2018). Can Future Managers and Business Executives be Influenced to Behave more Ethically in the Workplace? The Impact of Approaches to Learning on Business Students' Cheating Behavior, Journal of Business Ethics, vol. 149, Issue 1, pp. 245-258

BRodowsky, ET AL. (2020). Tolerance for Cheating From the Classroom to the Boardroom: A Study of Underlying Personal and Cultural Drivers, Journal of Marketing Education, Available at: https://journals-sagepub-com.ezproxy.uow.edu.au/doi/10.1177/o273475319878810 [Accessed 6th April 2020]

Flinders University. (2019). Student Academic Integrity Procedures, Flinders University - Inspiring Achievement, Available at: https://www.flinders.edu.au/content/dam/documents/staff/policies/ academic-students/student-academic-integrity-procedures.pdf [Accessed 4th January 2020]

GonZALEz, L. (2019). Aspiring pharmacists speak out after cheating leads to invalidated test scores, Fox26news, Available at: https:

//kmph.com/news/local/pharmacy-students-speak-out-after-test-results-are-invalidated [Accessed 4th January 2020]

GUERRERO-Dib ET AL. (2020). Impact of academic integrity on workplace ethical behaviour, International Journal for Educational Integrity, Vol. 16, Iss. 2, pp. 1-18, Available at: https://edintegrity.biomedcentral.com/articles/10.1007/s40979-020-0051-3 (Accesssed 6th April 2020)

KHAN, Z. R. (2014). Developing a factor-model to understand the impact of factors on higher education students' likelihood to e-cheat, Doctor of Philosophy thesis, School of Information Systems and Technology, University of Wollongong, https://ro. uow.edu. au/theses/4545

ICAI. (2020). Fundamental Values of Academic Integrity, International Center for Academic Integrity, Available at: https://www.academicintegrity.org/fundamental-values/ [Accessed 7th April 2020]

Koletsi-Kounari, H., Polychronopoulou, A., Reppa, C., \& Teplitsky, P. E. (2011). Penalties for Academic Dishonesty in a Greek Dental School Environment, Journal of Dental Education Oct 2011, 75 (10) 1383-1389, Available at http://www.jdentaled.org/content/75/10/1383/tab-article-info [Accessed 8th April 2020]

LASKY, J. (2017). Triage, Salem Press Encyclopedia of Health, p 7 [Accessed 4th January 2020]

Liberatore, M. J., Pollack-Johnson, B., \& Smith, C. A. (2001). Project Management in Construction: software use and research directions, Journal of construction engineering and management 127(2), pp. 101-107

Lim, \& SEe. (2001). Attitudes Toward, and Intentions to Report, Academic Cheating Among Students in Singapore, Ethics \& Behavior, Vol. 3, Iss. 11, pp. 261-274 [Accessed 7th April 2020]

LOVE, P. E. D., \& SMITH, J. (2003). Benchmarking, Benchaction and Becnlearning: rework mitigation in projects, Journal of Management in Engineering, 19(4), pp. 147-159

Maria, N. D. (2020). Support from Universities and Colleges, Available at https://www. ucas . com/ undergraduate/student-life/getting-student-support/support-universities-and-colleges [Accessed 8th April 2020] 
McKeE. (2014). Presenting Qualitative Survey Data with Word Clouds, Surveygizmo, Available at: https://www.surveygizmo.com/resources/blog/qualitative-data-word-cloud/ [Accessed 23rd May 2020]

Muola, J. M., \& Amukowa, W. (2018). The Virtue Of Academic Integrity: Prevalence, Antecedents And Intervention Measures, Proceeding of the 1st Annual International Conference held on 17th-19th April 2018, Machakos University, Kenya, Available at http://ir.mksu. ac.ke/bitstream/handle/123456780/ 740/THE\%2OVIRTUE\%200F\%2OACADEMIC\%2OINTEGRITY.pdf? sequence=1\&isAllowed=y [Accessed 7 th April 2020]

NIU. (2019). Causes of Academic Dishonesty, Northern Illinois University - Academic Integrity Tutorials, Available at: https://www.niu.edu/academic-integrity/students/causes/index.shtm] [Accessed 4th January 2020]

Ohme, A. M., IsaAcs, H. K., \& Trusheim, D. W. (2005). Survey Participation: a study of student experiences and response tendencies, Office of Institutional Research and Planning. University of Delaware. San Diego. CA. USA. [Online] Available URL:

WWW.udel.edu/IR/presentations/SurveyParticipation.ppt.

Olafson, L, Schraw, G., Nadelson, L., Nadelson, S., \& Kehrwald, N. (2013). Exploring the Judgement-Action Gap: College Students and Academic Dishonesty, Ethics E Behavior, Mar2013, Vol. 23, Issue 2, pp. 148-162.

RABBi, A. R. (2020). Humiliated by school, student commits suicide, Dhaka Tribune, Available at: https://wWw. dhakatribune.com/bangladesh/dhaka/2018/12/03/ humiliated-by-school-student-commits-suicide [Accessed 4th January 2020]

SHORE, K. (2002). Managing Cheating, Education world - connecting educators to what works, Available at: https://www.educationworld.com/a_curr/shore/shore023.shtml [Accessed 7th April 2020]

Singh, S., \& REMENYI, D. (2016). Plagiarism and ghostwriting: The rise in academic misconduct, South African Journal of Science, 112(5/6), pp. 36-42. doi: 10.17159/sajs.2016/2015030o.

Thompsun. (n.d.). Cheating in College, Education - Seattle PI, Available at: https://education. seattlepi.com/effects-students-caught-cheating-college-1219.html [Accessed 4th January 2020]

Ulster University, N. D. (2020). Triage, Available at https://www.ulster.ac.uk/wellbeing/triage [Accessed 8th April 2020]

UOW. (2019). What is academic misconduct, Available at: https://Www. uow.edu.au/about/governance/academic-integrity/students/misconduct/ [Accessed 4th January 2020]

USA TODAY. (2012). What did Obama say? His State of the Union speeches in word clouds, USA Today, Available at: https://www. usatoday.com/picture-gallery/news/politics/2014/o1/28/ what-did-obama-say-his-state-of-the-union-speeches-in-word-clouds/4966671/ [Accessed 24th May 2020]

Weimer, M. (2018). Cheating: Can We Be Doing More to Promote Academic Integrity?, Available at: https://www. teachingprofessor.com/for-those-who-teach/ cheating-can-we-be-doing-more-to-promote-academic-integrity/ [Accessed 4 January 2020]

Wood, B. D. (2010). Academic misconduct and detection, Radiologic Technology, 81(3), pp. 276-279. Available at: https://search-ebscohost-com.ezproxy.uow. edu. au/login. aspx?direct=true\&db=rzh\& $\mathrm{AN}=105296565 \&$ site=eds - live [Accessed: 7 April 2020] 


\section{Authors}

Dr Zeenath Reza Khan, University of Wollongong in Dubai, Knowledge Park, 20183 Dubai, United Arab Emirates, e-mail: zeenath.khan@gmail.com

Tina Ann Thomas, University of Wollongong in Dubai, United Arab Emirates, e-mail: TinaThomas@uowdubai.ac.ae

Vidhi Sharma, University of Wollongong in Dubai, United Arab Emirates, e-mail: vidhisharma@uowdubai.ac.ae 